\title{
Electroencephalographic Recordings During Withdrawal of Life-Sustaining Therapy Until 30 Minutes After Declaration of Death
}

\author{
Loretta Norton, Raechelle M. Gibson, Teneille Gofton, Carolyn Benson, \\ Sonny Dhanani, Sam D. Shemie, Laura Hornby, Roxanne Ward, G. Bryan Young
}

\begin{abstract}
Background: The timing of the circulatory determination of death for organ donation presents a medical and ethical challenge. Concerns have been raised about the timing of electrocerebral inactivity in relation to the cessation of circulatory function in organ donation after cardio-circulatory death. Nonprocessed electroencephalographic (EEG) measures have not been characterized and may provide insight into neurological function during this process. Methods: We assessed electrocortical data in relation to cardiac function after withdrawal of life-sustaining therapy and in the postmortem period after cardiac arrest for four patients in a Canadian intensive care unit. Subhairline EEG and cardio-circulatory monitoring including electrocardiogram, arterial blood pressure (ABP), and oxygen saturation were captured. Results: Electrocerebral inactivity preceded the cessation of the cardiac rhythm and ABP in three patients. In one patient, single delta wave bursts persisted following the cessation of both the cardiac rhythm and ABP. There was a significant difference in EEG amplitude between the 30-minute period before and the 5-minute period following ABP cessation for the group, but we did not observe any well-defined EEG states following the early cardiac arrest period. Conclusions: In a case series of four patients, EEG inactivity preceded electrocardiogram and $\mathrm{ABP}$ inactivity during the dying process in three patients. Further study of the electroencephalogram during the withdrawal of life sustaining therapies will add clarity to medical, ethical, and legal concerns for donation after circulatory determined death.
\end{abstract}

RÉSUMÉ: Enregistrements électroencéphalographiques pendant le retrait du maintien des fonctions vitales et jusqu'à 30 minutes après la constatation du décès. Contexte: Le moment de la détermination circulatoire de la mort à des fins de don d'organes présente un défi médical et éthique. Des préoccupations ont été soulevées concernant le moment de l'inactivité électrocérébrale en relation à l'arrêt de la fonction circulatoire dans le contexte de don d'organes après la mort cardio-circulatoire. Les mesures électroencéphalographiques (EEG) brutes n'ont pas été caractérisées et pourraient fournir des indices sur la fonction neurologique pendant ce processus. Méthodologie: Nous avons analysé des données électrocorticales en relation à la fonction cardiaque après le retrait du maintien des fonctions vitales et dans la période postmortem, après l'arrêt cardiaque, chez 4 patients hospitalisés dans une unité canadienne de soins intensifs. Nous avons recueilli le tracé EEG sous la lisière des cheveux et la surveillance cardio-circulatoire incluant l'électrocardiogramme, la tension artérielle (TA) et la saturation en oxygène. Résultats: L'inactivité électrocérébrale a précédé la cessation du rythme cardiaque et de la TA chez 3 patients. Nous avons observé une différence significative de l'amplitude de l'EEG entre la période de 30 minutes avant et la période de 5 minutes après l'arrêt de la TA dans ce groupe de patients, mais nous n'avons pas observé d'état bien défini à l'EEG immédiatement après l'arrêt cardiaque. Conclusions: Chez une série de 4 patients, l'inactivité à l'EEG a précédé l'inactivité électrocardiographique et l'arrêt de la TA pendant le processus de la mort chez 3 patients. Des études ultérieures sur l'électroencéphalogramme pendant le retrait du maintien des fonctions vitales aideront à clarifier les préoccupations médicales, éthiques et légales concernant le don d'organes après la détermination circulatoire de la mort.

Keywords: Critical care, Electrocerebral inactivity, Determination of death, Donation after circulatory death, EEG, Intensive care, Neurocritical care, Palliative care, Vital signs, withdrawal of life sustaining therapies

doi:10.1017/cjn.2016.309

Can J Neurol Sci. 2017; 44: 139-145

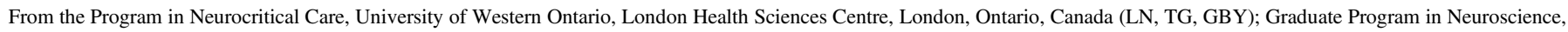
University of Western Ontario, London, Ontario, Canada (LN); Department of Psychology, University of Western Ontario, London, Ontario, Canada (RMG); Department of Clinical

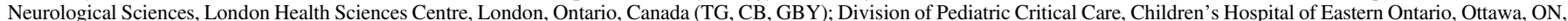

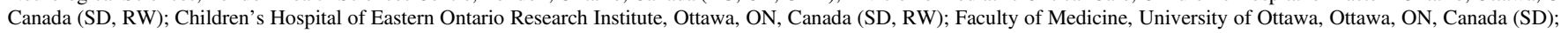

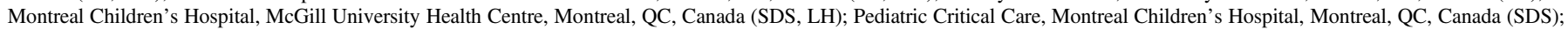

Faculty of Pediatrics, McGill University, Montreal, QC, Canada (SDS); McGill University Health Centre Research Institute, Montreal, QC, Canada (LH). Received August 21, 2015. Final Revisions Submitted March 16, 2016. Date of Acceptance April 15, 2016.

Correspondence to: Loretta Norton, The Brain and Mind Institute, Room 120K, Natural Sciences Building, The University of Western Ontario, London, Ontario, N6A 5B7

Email: lnorton4@uwo.ca. 
The cessation of brain activity during the dying process before and after cardiac arrest is understudied, physiologically important, and even ethically charged when it precedes organ donation. Physicians have expressed concerns regarding the state of cerebral activity during the dying process. Surveys of pediatric physicians, for example, show that $11 \%$ are concerned that patients may be able to experience pain during this period. ${ }^{1}$ Cerebral function is particularly important in the context of organ donation after cardio-circulatory death (DCD), where death is declared 2 to 10 minutes following the cessation of circulatory function. ${ }^{2-5}$ DCD most commonly involves patients with catastrophic brain injury who do not fulfill brain death criteria and where there has been a consensual agreement for the withdrawal of life-sustaining therapy (WLST). Because the time between withdrawing support, pronouncing death, and procuring organs is relatively short, there has been some uncertainty about possible cerebral or cognitive function during this process.

The goal of the present study was to quantify nonprocessed electroencephalographic (EEG) in humans at the time of WLST. EEG can be used to determine when the loss of electrocerebral activity occurs. In fact, processed EEG through the use of bispectral index (BIS) monitoring has described a spike in EEG activity at the time of death ${ }^{6}$ and during donation after circulatory death. ${ }^{7}$ Borjigin et al (2013) described a similar finding of increased EEG coherence and connectivity in the rat brain following cardiac arrest. Nonprocessed EEG at the time of WLST has not yet been prospectively studied in humans and may provide insight into neurological function during the dying process. In the present work, we assess subhairline EEG in relation to cardiac function after WLST and in the immediate postmortem period after cardiac arrest.

\section{Materials ANd Methods}

This substudy, specifically examining EEG activity during WLST, was part of a larger prospective observational pilot study to monitor the physiological changes that occur after death from cardiac arrest at five Canadian intensive care units. ${ }^{9}$ The study was approved by our local institutional Research Ethics Board for Health Sciences Research Involving Human Subjects, and written informed consent was obtained according to the Declaration of Helsinki from the legally authorized representative of each patient.

\section{Participants}

We report four patients who were hospitalized in the medicalsurgical intensive care unit at the London Heath Sciences Centre University Hospital, London, Ontario, Canada (Table 1). All patients had continuous EEG in addition to cardio-circulatory monitoring including: electrocardiogram (ECG), arterial blood pressure (ABP), and oxygen saturation during WLST. None of the patients met the criteria for brain death at the time of WLST nor did any of the patients undergo DCD. Patients 1,2 , and 4 were eligible for DCD but their families declined donation because of the previously expressed wishes of the patient. Patient 3 was medically unsuitable for organ donation because of multiorgan failure and a previous history of invasive breast cancer; however, this patient was an eligible tissue donor and a bilateral donor enucleation procedure was performed. In accordance with standard local protocols, all patients were receiving analgesics/sedatives, including fentanyl, morphine, and midazolam, at the time of WLST (Table 1). In all patients, death was declared by the attending team based on the absence of heart sounds by auscultation, absent palpable pulse, absent breath sounds by auscultation, unresponsiveness to painful stimulus, and unreactive pupils. Other than continuous monitoring of circulatory and neurological variables collected remotely, there was no change in patient care during WLST.

\section{Signal Acquisition}

We used a four-channel bipolar EEG monitor (Datex-Ohmeda S/5 M-EEG Module; model \#898683-00) with a Datex-Ohmeda Critical Care monitor (GE Healthcare, Helsinki, Finland). This system has been validated for use in the intensive care unit. ${ }^{10}$ The subhairline bipolar montage uses one ground and eight anterior surface electrodes (3M Red Dot 2670-5). The EEG module has a sampling frequency of $100 \mathrm{~Hz}$ per channel featuring an online bandpass filter of 0.5 to $30 \mathrm{~Hz}$, and the module offers an amplitude

Table 1: Demographic data

\begin{tabular}{|c|c|c|c|c|c|c|c|c|c|c|}
\hline \multirow[b]{2}{*}{ Patient } & \multirow[b]{2}{*}{ Age } & \multirow[b]{2}{*}{ Gender } & \multirow[b]{2}{*}{$\begin{array}{l}\text { Admitting } \\
\text { diagnosis }\end{array}$} & \multicolumn{4}{|c|}{ At WLST } & \multirow[b]{2}{*}{ Sedation after WLST } & \multicolumn{2}{|c|}{ At isoelectric EEG } \\
\hline & & & & GCS & $A \mathrm{BP}$ & HR & EEG & & $\mathbf{A B P}$ & HR \\
\hline 1 & 72 & $\mathrm{~F}$ & $\begin{array}{r}\text { Subarachnoid } \\
\text { hemorrhage }\end{array}$ & $5 \mathrm{~T}$ & $118 / 42$ & 93 & $\begin{array}{l}\text { Burst suppression patterns with } \\
\text { bursts of delta activity; } \\
\text { possible drug spindles }\end{array}$ & $\begin{array}{l}\text { Morphine infusion } 10 \mathrm{mg} / \\
\text { hour, midazolam } \\
\text { infusion } 10 \mathrm{mg} / \mathrm{hour}\end{array}$ & $59 / 34$ & 52 \\
\hline 2 & 70 & M & Cardiac arrest & $3 \mathrm{~T}$ & $116 / 59$ & 85 & $\begin{array}{l}\text { Generalized suppression with } \\
\text { slow wave delta }\end{array}$ & $\begin{array}{l}\text { Morphine infusion } 8 \text { - } \\
20 \mathrm{mg} / \text { hour }+2 \text { boluses } \\
4 \mathrm{mg} / \mathrm{mcg} / . \\
\text { Midazolam } 6-10 \mathrm{mg} / \mathrm{hour} \\
+4 \text { boluses of } 4 \mathrm{mg} / \\
\text { mcg }\end{array}$ & $123 / 59$ & 82 \\
\hline 3 & 58 & $\mathrm{~F}$ & $\begin{array}{l}\text { Radiation } \\
\text { pneumonitis }\end{array}$ & $6 \mathrm{~T}$ & $105 / 55$ & 152 & $\begin{array}{l}\text { Burst suppression patterns } \\
\text { with bursts of delta activity }\end{array}$ & $\begin{array}{l}\text { Fentanyl boluses ( } 3 \text { ) } \\
100 \mu \mathrm{g}\end{array}$ & $40 / 22$ & 73 \\
\hline 4 & 67 & M & Cardiac arrest & $3 \mathrm{~T}$ & $129 / 52$ & 113 & Delta and theta activity & $\begin{array}{l}\text { Fentanyl infusion 100- } \\
300 \mathrm{mcg} / \text { hour/ } \\
\text { Midazolam boluses ( } 3 \text { ) } \\
1 \mathrm{mg} / \mathrm{mcg}\end{array}$ & - & - \\
\hline
\end{tabular}

ABP, arterial blood pressure; GCS, Glasgow Coma Scale; HR, heart rate. 
range of $\pm 400 \mathrm{mV}$ with a resolution of $60 \mu \mathrm{V}$. Electrode impedances were below $5 \mathrm{k} \Omega$.

\section{Signal Analyses}

Signal analysis included the calculation of EEG power spectra and trending of EEG amplitude and 95\% spectral edge frequency (the power, or square of the amplitude, as a function of frequency where $95 \%$ of the EEG activity is below this frequency) over time. The absence of electrocerebral activity was defined as amplitude of less than $2 \mu \mathrm{V}$ following the recommended guidelines for EEG testing in brain death. ${ }^{11} \mathrm{ABP}$ cessation was defined a priori as absent ABP waveform tracing for a period of 1 minute. Physiological data including the mean EEG amplitude and the 95\% spectral edge frequency were averaged across channels in 30-second epochs.

To assess the cessation of brain activity in relation to other physiological measures during the dying process, we collected heart rate, ABP through an intra-arterial catheter, pulse oximetry, and EEG signals continuously beginning 30 minutes before WLST until 30 minutes following the declaration of death. We were particularly interested in the EEG activity during the 5-minute observation period after ABP cessation, in keeping with current Canadian guidelines for procuring organs in DCD patients that state that organs should not be procured until the 5-minute period has elapsed to confirm irreversibility of cardio-circulatory arrest. ${ }^{4} \mathrm{We}$ also investigated EEG activity at the time of final ECG cessation to determine if there were any well-defined EEG states following the early cardiac arrest period as previously observed in rats. ${ }^{8}$

\section{Power Analyses}

EEG spectrograms were calculated using a discrete Fourier transform with a 2-second segment size and 1-second overlap for each frequency bin $(0.5-30 \mathrm{~Hz}$ with $0.5 \mathrm{~Hz}$ bin size $)$ using Fieldtrip ${ }^{12}$ implemented via custom MATLAB script (MathWorks, Inc., Natick, MA). Each segment was windowed with a Hanning window, and the absolute power was expressed in a log scale averaged over all four bipolar channels. The mean and standard error of absolute power was calculated for eight frequency bands defined as follows: delta $(0-4 \mathrm{~Hz})$, theta $(4-8 \mathrm{~Hz})$, alpha $(8-12 \mathrm{~Hz})$, and beta $(12-30 \mathrm{~Hz})$. No artefact correction procedure was performed.

\section{Results}

\section{Physiology and EEG Before and after Cessation of ABP}

Figure 1 shows the physiological measures for all four patients before and following cardio-circulatory death.

For patient 1, electrocerebral inactivity preceded the cessation of $\mathrm{ABP}$ and ECG by 4 minutes. Of note, ECG and ABP restarted 1 minute and 20 seconds after the initial stop for 40 seconds. Throughout this period, the EEG did not demonstrate evidence of electrocerebral activity as EEG amplitude remained less than $2 \mu \mathrm{V}$.
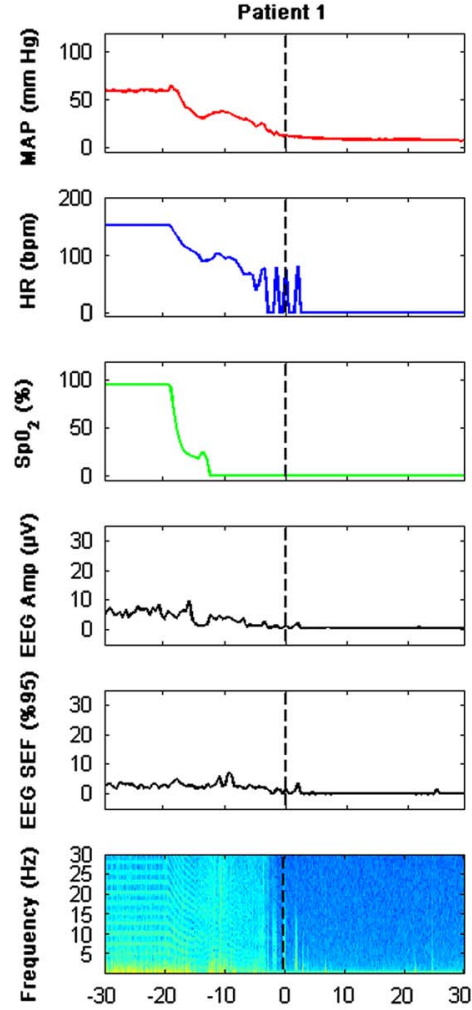
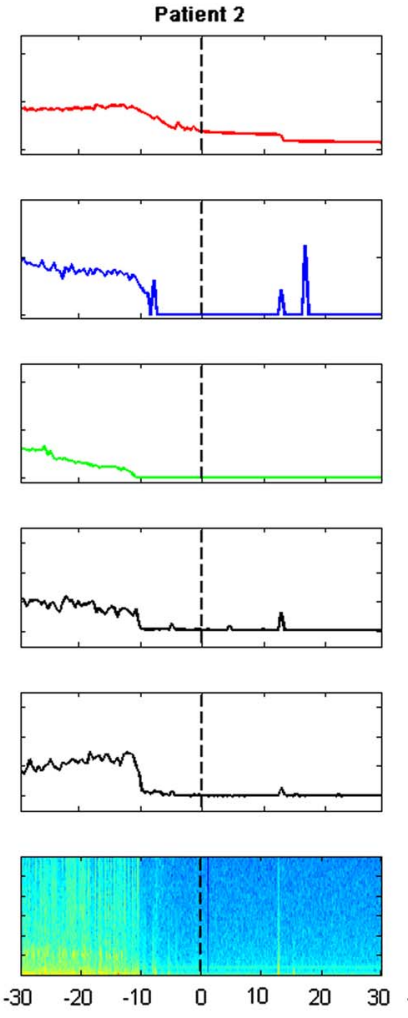
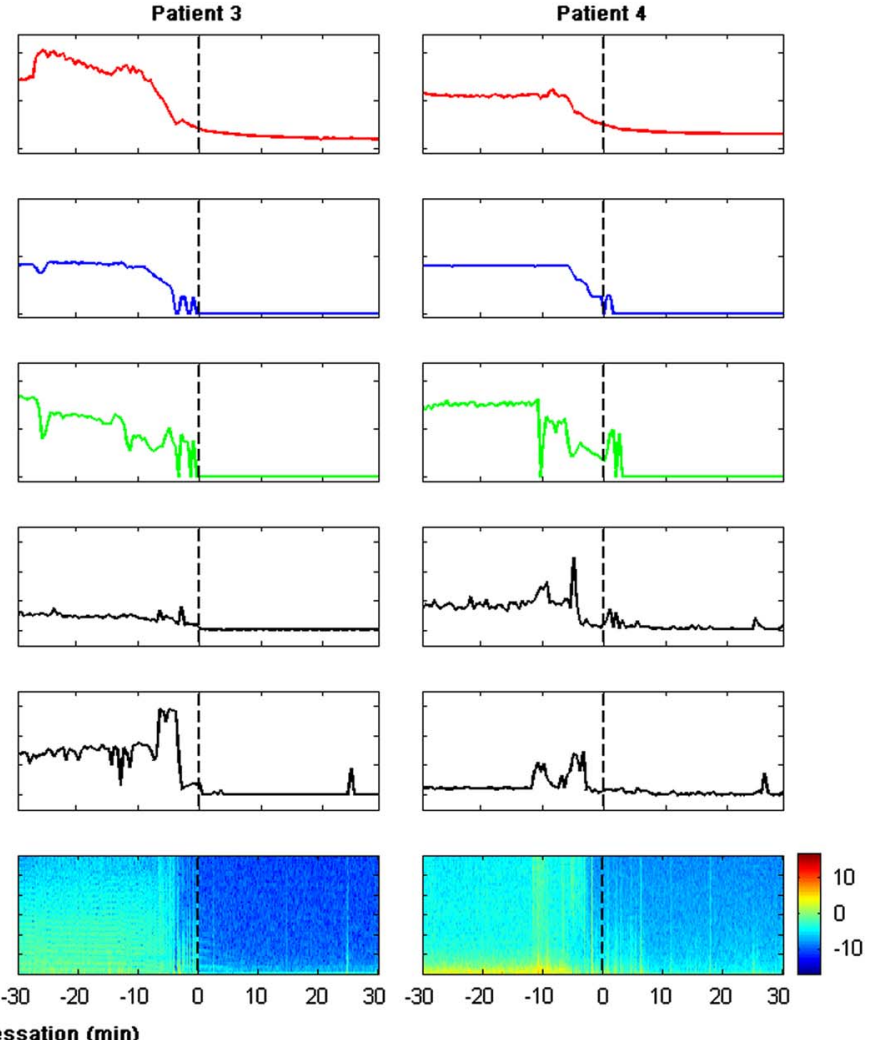

Figure 1: Change in all physiological measurements at or before cessation of ABP. (A) Physiological data for each patient over a 1-hour period that shows 30 minutes before and 30 minutes following cessation of ABP (time zero with hashed line). From top to bottom: mean arterial pressure $(\mathrm{MAP})$, heart rate $(\mathrm{HR})$, plethysmography $\left(\mathrm{SpO}_{2}\right)$, mean EEG amplitude, mean EEG spectral edge frequency (95\%), and EEG absolute power averaged across all four EEG channels. The $z$ axis of the spectrogram uses a log scale from \pm 17.0 to indicate power (low log power values in blue and high log power values in red). 
For patient 2, electrocerebral inactivity preceded the cessation of ABP and ECG by 10 minutes and 10 seconds.

Patient 3 had a burst in power in higher frequency ranges 8 minutes before ABP cessation for a period of 4 minutes and electrocerebral inactivity occurred 1 minute and 30 seconds before the cessation of ABP.

In patient 4, initial high-frequency EEG activity was seen at two time points: 11 minutes and 5 minutes before ABP cessation for a period of 2 minutes each time. ECG continued for an additional 15 minutes and 30 seconds following ABP cessation. The EEG showed increasing suppression with infrequent single delta wave bursts following ECG and ABP cessation. These delta bursts continued for 10 minutes and 38 seconds following ECG cessation with a mean amplitude of $4.52 \mu \mathrm{V}$ in the last burst of delta activity (Figure 2).

A significant difference in EEG mean amplitude was found for the group between the 30 minutes before ABP cessation and the 5 minutes following ABP cessation, $(t(3)=8.473, \mathrm{p}=.003)$. Mean amplitude before ABP cessation was significantly greater than mean amplitude following ABP cessation $\left(M_{\text {pre }}=5.785 \mu \mathrm{V}\right.$, $\mathrm{SE}=0.983 ; M_{\text {post }}=1.2188 \mu \mathrm{V}, \mathrm{SE}=0.539$ ).

We also compared mean spectral power for the group across the four frequency bands of interest for the 30 minutes before and 5 minutes following ABP cessation. There were no significant effects $(p>0.10)$ (Figure 1).

\section{EEG at ECG Cessation}

A spectrogram of EEG power comparing 1 minute before ECG cessation to 1 minute following ECG cessation shows no change in patients 2 and 4 and a dramatic change in patients 1 and 3 (Figure 3). However, the raw EEG waveforms suggest that the change in EEG power for patients 1 and 3 is related to ECG artefact just before ECG cessation (Figure 3 ). The EEG and ECG signals are significantly correlated in these cases $(R=-0.051$ to $0.093 ; \mathrm{p}<0.0001)$.

\section{DISCUSSION}

Through the use of EEG, we assessed the brain activity of four patients during the WLST and through the immediate postmortem period after cardiac arrest. Prior reports of human brain activity in this period have relied upon a proprietary integer-based measure known as BIS. BIS monitoring is typically used in clinical practice to monitor the depth of anesthesia. Although BIS seems to be an effective measure of neural activity in paralyzed patients, its effects in nonparalyzed patients are not well-understood, and it is sensitive to artefacts. ${ }^{13-16}$

Surface EEG activity was used to infer brain function as it is known to reflect the net contribution of postsynaptic potentials from cortical pyramidal cells. ${ }^{17}$ Using direct, simultaneous recordings in animals and through modelling studies, researchers have recently found evidence that EEG is strongly correlated with the multiunit activity of large cortical neuronal populations. ${ }^{18-20}$ Additionally, EEG correlates with brain metabolism. There is evidence from both experimental and clinical studies that EEG reflects the oxidative metabolism of brain tissue and cerebral blood flow (CBF). ${ }^{21}$ For example, coma and general anesthesia give rise to a slow-wave EEG and reduced cerebral oxygen uptake and blood flow. ${ }^{22,23}$ Changes in regional CBF coincide with a flattening of the EEG when CBF falls below a critical level (16-22 ml/100 g/minute; internal carotid pressure to $29-50 \mathrm{mmHg}$ ). ${ }^{24}$ Interestingly, during hypoxia, EEG frequency and $\mathrm{CBF}$ are often not correlated. ${ }^{24}$ This is aligned with our findings of a statistically significant change in EEG amplitude between the 30-minute period before and the 5-minute period following ABP cessation but no difference in spectral frequency. Thus, amplitude analyses may be more sensitive than examination of frequency in detecting changes in the EEG during the dying process because of diminished $\mathrm{CBF}$.

Cerebral inactivity preceded the cessation of ECG and ABP in three of four patients. An unexpected finding in the current work was that single bursts of delta wave activity persisted following ECG and ABP cessation for one patient. It is difficult to posit a physiological basis for this EEG activity given that it occurs after a prolonged loss of circulation. These waveform bursts could, therefore, be artefactual in nature, although an artefactual source could not be identified.

We also examined brain activity around the time of ECG cessation. A high amplitude slow wave or "delta blip" has been reported within 1 minute of decapitation in rats thought to be indicative of synchronous neuronal death. ${ }^{25}$ We did not observe a

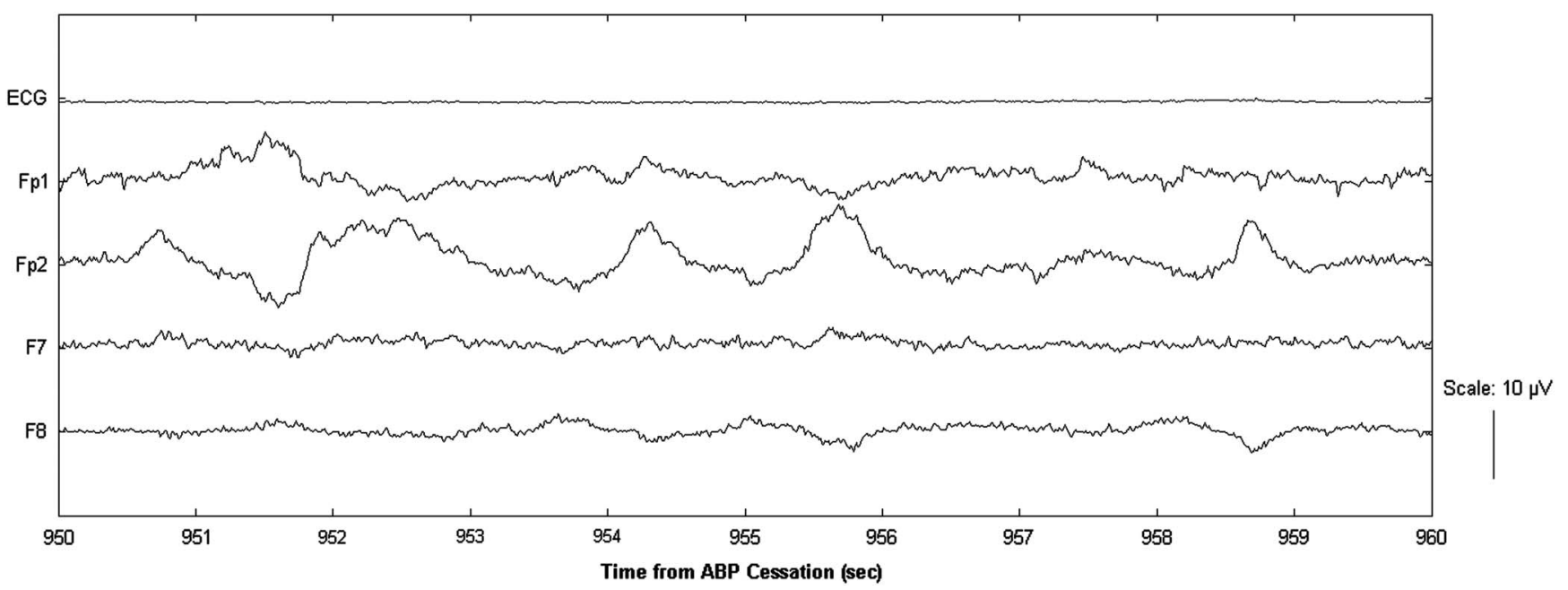

Figure 2: Raw EEG tracing in patient 4 following declaration of death. Representative tracing of large infrequent single delta wave bursts observed for 10 minutes and 38 seconds (EEG bottom four tracings) following the loss of ECG tracing (top tracing). 

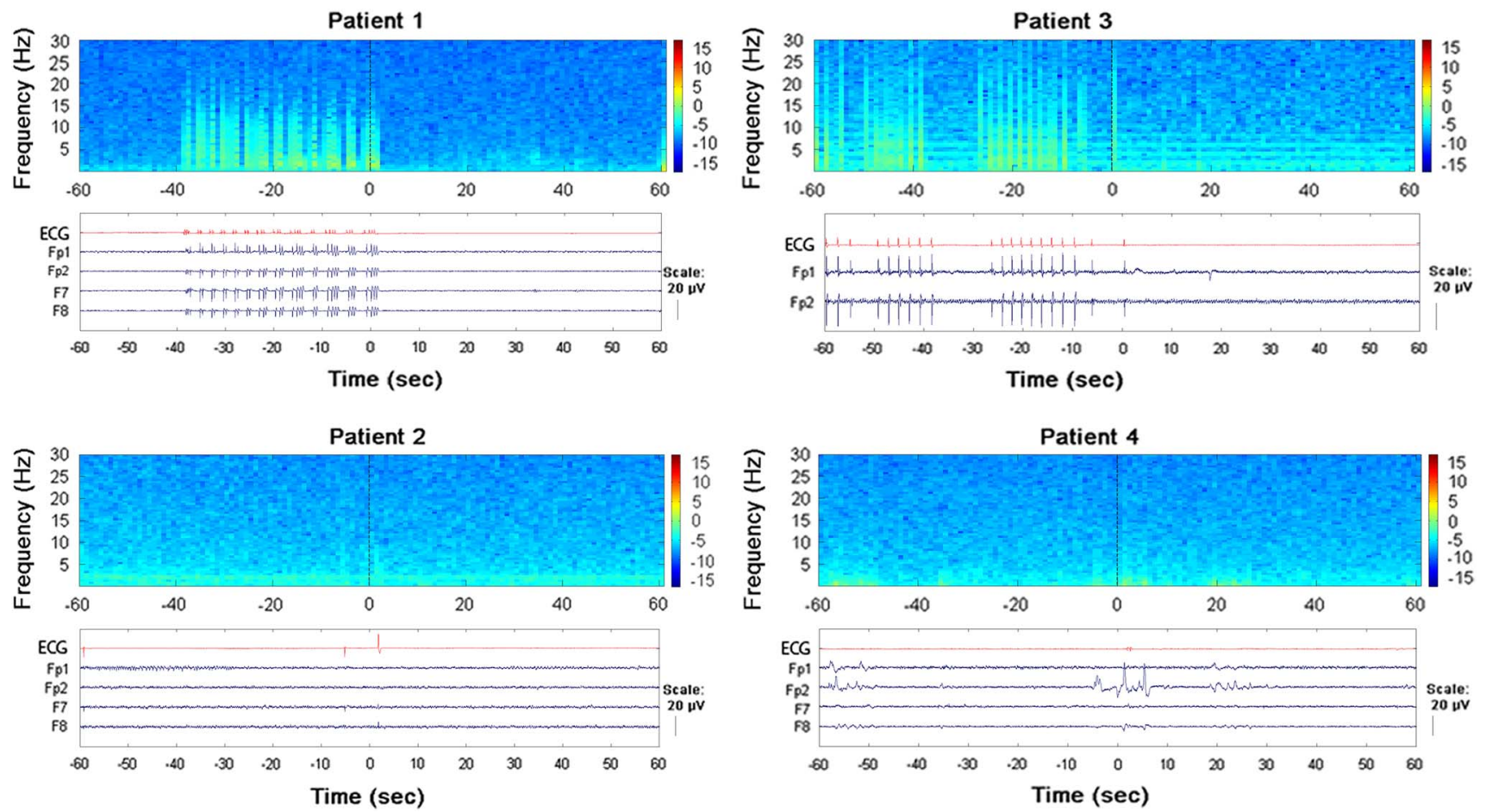

Figure 3: EEG power spectrograms at the early cardiac arrest period. Spectrograms depict 1 minute before and 1 minute following cessation of the ECG rhythm. The $x$ axis is time relative to the cessation of ECG with time 0 (denoted with a hatched line) as the last heartbeat. The $z$ axis of the spectrogram uses a log scale from \pm 17.0 to indicate power (low log power values in blue and high log power values in red).

delta wave within 1 minute following cardiac arrest in any of our four patients. We also did not observe any well-defined EEG states following the early cardiac arrest period as previously reported in rats. ${ }^{8}$ In fact, EEG activity declined dramatically well before the last heartbeat for two patients, and we noted ECG artefact in EEG channels for two patients within 1 minute before ECG cessation.

In line with previous work using BIS, ${ }^{6,7}$ two patients showed some power in higher frequency ranges before $\mathrm{ABP}$ cessation alongside an increase in $95 \%$ spectral edge frequency immediately before death. These previous reports from patients with no sedation are consistent with our findings from patients receiving sedation and suggest that the common finding of high-frequency activity before death might be a common feature of the dying process regardless of sedation. High-frequency synchronous gamma oscillations $(25-100 \mathrm{~Hz})$ have also been reported in the rat brain for up to 30 seconds following cardiac arrest. ${ }^{8}$ Moreover, it has been proposed that this apparent increase in neuronal activity around the time of death may reflect near-death experiences. ${ }^{6}$ In the current work, visual inspection of the raw EEG tracing by an experienced electroencephalographer revealed that the increased activity before $\mathrm{ABP}$ cessation could be an electromyelogram (EMG) artefact. Thus, one must be careful about false positive EEG signals from muscular and/or cardiac sources.

\section{Limitations}

Because we report a case series of four patients, it is not possible to make generalizable inferences about our findings. Furthermore, physiological artefacts, including those generated by EMG, ECG, and sweat, and nonphysiological artefacts, including line noise from medical equipment and movement of staff and family members at the bedside, are common in the intensive care unit and very difficult to avoid in a study of this nature. Moreover, our subhairline EEG montage only captured frequencies up to $30 \mathrm{~Hz}$ at anterior sites on the forehead. The subhairline EEG was used rather than a full 10-20 EEG montage because the device was already in place before WLST to monitor EEG activity. In our intensive care unit, we often use the subhairline EEG for continuous EEG monitoring as a standard of care in our patients. The presented four cases were a subset of a larger study, ${ }^{9}$ which was a noninterventional, observational study to describe the physiology from waveform data collected from the critical care monitors during the dying process. The larger study design required no deviations from the standard practice for WLST other than leaving current monitoring devices in place for 30 minutes post clinical determination of death. As a result of participating in the study, no other intervention or changes in care of the patient were permitted, thus precluding the application of a complete 10-20 EEG recording. As such, some of the guidelines for cerebral death recording suggested by the American Clinical Neurophysiology Society ${ }^{11}$ could not be met. Electrode pairs were unable to be placed $10 \mathrm{~cm}$ apart, and this may have prevented detection of some cerebral potentials that could be observed with longer interelectrode distances. Additionally, only anterior portions of the brain were covered with the subhairline EEG; this limited scalp coverage reduces our ability to determine whether the observed absence of EEG activity occurred across the entire cerebrum.

\section{Clinical Significance}

This is the first study, to our knowledge, that depicts cessation of anterograde blood flow and neurological function through simultaneous measurement of ABP and EEG. Results of this small patient 
sample indicate that it is ethically and logistically feasible to collect EEG recordings concurrently with other physiological measurements during the dying process. The most clinically significant finding was a substantial decline in neurological activity before cardiac inactivity in the majority of patients. As in prior studies of humans and rats, high-frequency EEG activity increased just before the time of death in two patients, indicating that this might be a common feature of the neurological dying process. Another intriguing clinical finding included one incident of a very brief resumption of cardiac activity after a period of absence without concurrent resumption of neurological activity. Finally, we also encountered one case where EEG activity persisted beyond the cessation of ABP. Given that this was only observed in one case and it persisted well beyond the loss of circulation, we speculate that this activity could reflect a nonneuronal artefact. Although our case series provides a proof of concept for the feasibility for the assessment of neurological function at the time of death, we have several recommendations for future research to better inform clinical practice around the determination of death, especially in the context of DCD.

Future EEG studies of the dying brain should be designed to have a higher sampling rate to study gamma oscillations and the use of the full 10-20 montage for complete scalp coverage and standardized reproducibility. EMG should also be independently evaluated as it occurs in high frequency ranges and can contaminate EEG signals. It would also be advantageous to study brainstem function during the dying process through the use of evoked potentials to determine when brainstem function ceases relative to heart function.

\section{Conclusion}

For the first time, we prospectively studied subhairline EEG activity compared with ECG and ABP waveforms at the time of death in a small sample of patients undergoing the WLST. In our case series, we found a significant difference in EEG amplitude between the 30-minute period before the cessation of ABP to the 5-minute period following ABP cessation. Larger prospective studies involving the use of EEG and evoked potentials should be conducted to describe when cerebral and brainstem activity ceases in relation to other physiological variables in the dying patient to better inform the process of DCD.

\section{ACKNOWLEDGMents AND Funding}

This study was conducted at the medical-surgical intensive care unit at the London Health Sciences Centre - University Hospital, London, Ontario, Canada. The work was conducted for the Determination of Death Practices in Intensive Care (DDePICt) DDEPICT Investigator Group, the Canadian Critical Care Trials Group, and the Loeb Chair and Research Consortium in Organ and Tissue Donation. The work was supported, in part, by grants from the Children's Hospital of Eastern Ontario Research Institute, Physician's Services Incorporated, and Canadian Institutes for Health Research (CIHR). LN was supported by a Canada Graduate Scholarship from CIHR, and RMG was supported by a Vanier Canada Graduate scholarship.

\section{Disclosures}

$\mathrm{LN}$ is a doctoral student and receives a scholarship from CIHR. RG: Vanier Canada Graduate Scholarship, doctoral student and scholarship. SD is chief medical officer and receives a salary stipend from Trillium, Gift of Life Network; is a principal investigator and received a grant from Children's Hospital Eastern Ontario; is a principal investigator and received a grant from Physician Services, Ontario; is a principal investigator for and received a CIHR Meeting Grant. BY has provided consultation in developing a bedside EEG monitor for ICU recordings (no compensation) from GE Healthcare. $\mathrm{SS}$ is an advisor and received a consulting fee from Canadian Blood Services (government agency). TG is an examining neurologist for the SURTAVI trial and received an honorarium from Medtronic. $\mathrm{CB}, \mathrm{LH}$, and RW do not have anything to disclose.

\section{REFERENCES}

1. Sarnaik AA, Clark JA, Meert KL, Sarnaik AP. Views of pediatric intensive care physicians on the ethics of organ donation after cardiac death. Crit Care Med. 2013;41:1733-44.

2. University of Pittsburgh Medical Center Policy and Procedure Manual. Kennedy Institute of Ethics, 1993. Available from: http:// hosped.umc.edu/education/documents/CL.P9PCAPump.pdf.

3. Reich DJ, Mulligan DC, Abt PL, et al. ASTS recommended practice guidelines for controlled donation after cardiac death organ procurement and transplantation. Am J Transplant. 2009;9:2004-11.

4. Shemie SD, Baker AJ, Knoll G, et al. Donation after cardiocirculatory death in Canada. CMAJ. 2006;175:S1-24.

5. Dhanani S, Hornby L, Ward R, Shemie S. Variability in the determination of death after cardiac arrest: a review of guidelines and statements. J Intensive Care Med. 2012;27:238-52.

6. Chawla LS, Akst S, Junker C, Jacobs B, Seneff MG. Surges of electroencephalogram activity at the time of death: a case series. J Palliat Med. 2009;12:1095-100.

7. Auyong DB, Klein SM, Gan TJ, Roche AM, Olson D, Habib AS. Processed electroencephalogram during donation after cardiac death. Anesth Analg. 2010;110:1428-32.

8. Borjigin J, Lee U, Liu T, et al. Surge of neurophysiological coherence and connectivity in the dying brain. Proc Natl Acad Sci. 2013;110:1-6.

9. Dhanani S, Hornby L, Ward R, et al. Vital signs after cardiac arrest following withdrawal of life-sustaining therapy: a multicenter prospective observational study. Crit Care Med. 2014;42:2358-69.

10. Young GB, Sharpe MD, Savard M, Al Thenayan E, Norton L, Davies-Schinkel C. Seizure detection with a commercially available bedside EEG monitor and the subhairline montage. Neurocrit Care. 2009;11:411-6.

11. American Clinical Neurophysiology Society. Guideline 3: minimum technical standards for EEG recording in suspected cerebral death. J Clin Neurophysiol. 2006;23:97-104.

12. Oostenveld R, Fries P, Maris E, Schoffelen J-M. FieldTrip: open source software for advanced analysis of MEG, EEG, and invasive electrophysiological data. Comput Intell Neurosci. 2011;2011:156869.

13. Bruhn J, Bouillon TW, Shafer SL. Electromyographic activity falsely elevates the bispectral index. Anesthesiology. 2000;92:1485-7.

14. Renna M, Wigmore T, Mofeez A, Gillbe C. Biasing effect of the electromyogram on BIS: a controlled study during high-dose fentanyl induction. J Clin Monit Comput. 2002;17:377-81.

15. Vivien B, Di Maria S, Ouattara A, Langeron O, Coriat P, Riou B. Overestimation of Bispectral Index in sedated intensive care unit patients revealed by administration of muscle relaxant. Anesthesiology. 2003;99:9-17.

16. Wennervirta J, Salmi T, Hynynen M, et al. Entropy is more resistant to artifacts than bispectral index in brain-dead organ donors. Intensive Care Med. 2007;33:133-6.

17. Eccles JC. Interpretation of action potenials evoked in the cerebral cortex. EEG Clin Neurophysiol. 1951;3:449-64.

18. Murakami S, Okada Y. Contributions of principal neocortical neurons to magnetoencephalography and electroencephalography signals. J Physiol. 2006;575:925-36.

19. Mazzoni A, Whittingstall K, Brunel N, Logothetis NK, Panzeri S. Understanding the relationships between spike rate and delta/ gamma frequency bands of LFPs and EEGs using a local cortical network model. Neuroimage. 2010;52:956-72. 
20. Whittingstall K, Logothetis NK. Frequency-band coupling in surface EEG reflects spiking activity in monkey visual cortex. Neuron. 2009;64:281-9.

21. Ingvar DH, Sjolund B, Ardo A. Correlation between dominant EEG frequency, cerebral oxygen uptake and blood flow. Electroenchphalgr Clin Neurophysiol. 1976;41:268-76.

22. Ingvar DH. Cerebral blood flow and metabolism related to EEG and cerebral functions. Acta Anaesthesiol Scand. 1970;15:110-4.
23. Brown EN, Lydic R, Schiff ND. General anesthesia, sleep, and coma. N Engl J Med. 2011;363:2638-50.

24. Trojaborg W, Boysen G. Relation between EEG, regional berebral blood flow and internal carotid artery pressure during carotid endarterectomy. Electroencephalogr Clin Nurophysiol. 1973;69:61-9.

25. van Rijn CM, Krijnen H, Menting-Hermeling S, Coenen AML. Decapitation in rats: latency to unconsciousness and the "wave of death." PLoS One. 2011;6:e16514. 